\title{
ÍNDICES TÉRMICOS PARA A IDENTIFICAÇÃO DE ONDAS DE CALOR APLICADOS AO ESTADO DO PARANÁ, BRASIL.
}

THERMAL INDEXES FOR THE IDENTIFICATION OF HEAT WAVES APPLIED TO STATE OF PARANÁ, BRAZIL.

\author{
Karitha Campos Kogima'; Deise Fabiana Ely \\ 1 Universidade Estadual de Londrina (UEL), Londrina, PR, Brasil
}

Correspondência para: Deise Fabiana Ely (deise.ely@gmail.com)

doi: 10.12957/geouerj.2019.40947

Recebido em: 15 ago. 2018 | Aceito em: 01 nov. 2018

\section{RESUMO}

O objetivo do presente estudo foi produzir uma análise da variabilidade das temperaturas máximas anuais no estado do Paraná no período de 1976 a 2015 para identificar a ocorrência de períodos de extremos de calor. Para tanto foram aplicados dois diferentes índices: 1) primavera - verão (P-V) e 2) índice diário (ID). O índice P-V permite detectar somente os eventos mais extremos e, no Paraná, foi verificado que estes ocorrem com maior frequência nos meses de novembro a fevereiro. $O$ índice ID identifica os eventos de aquecimento anômalo que ocorrem durante todo o ano e foi constatado que os maiores registros ocorrem nas estações de outono e inverno. Por meio da análise de tais índices foi possível identificar que as estações localizadas na região norte e oeste do estado, principalmente aquelas localizadas ao norte do trópico de Capricórnio, apresentaram ondas de calor mais significativas, de maior duração e com temperaturas mais elevadas. Por outro lado, as estações situadas no centro-sul registraram ondas de calor com menor intensidade e duração. Em virtude do fato das ondas de calor serem caracterizadas de formas diferentes pelos métodos aplicados, destaca-se que os resultados são dependentes do índice utilizado, sendo assim, a seleção do critério para determinar as ondas de calor depende do propósito do estudo.

Palavras-chave: extremos térmicos. Índices. ondas de calor. Paraná.

\section{ABSTRACT}

The purpose of this work is to analyze the variability of the maximum annual temperatures in the state of Parana from 1976 to 2015 to identify the occurrence of periods of extreme heat. Two different indexes were applied: 1) spring summer $(P-V)$ and 2) daily index (ID). The P-V index allows you to detect only the most extreme events. It was found that they occur more frequently in the months of November to February. The ID index identifies the anomalous warming events that occur throughout the year. It was found that the largest records occur in the autumn and winter seasons. Analyzing both indices it was possible to discover that the stations located in the northern and western regions of Paraná, mainly those located north of the Tropic of Capricorn, presented more significant heat waves, with longer duration and with higher temperatures. On the other hand, the stations located in the center-south registered heat waves with less intensity and duration. Due to the fact that the heat waves are characterized in different ways by the applied methods, the results are dependent on the index used, so the selection of the criterion to determine the heat waves depends on the purpose of the study.

Keywords: thermal extremes. Indices. heat waves. Paraná

\section{INTRODUÇÃO}

Conhecer a dinâmica climática é uma forma de explicar os fenômenos naturais que ocorrem em determinada localidade, logo são os elementos atmosféricos que interferem e caracterizam as condições 
do tempo (temperatura, umidade do ar, chuva, vento, pressão atmosférica, etc.). Mendonça (2007, 2001, p. 42) caracteriza o estudo do clima como sendo o que "[...] trata dos padrões de comportamento da atmosfera em suas interações com as atividades humanas e com a superfície do planeta, durante um longo período". Por meio desta citação, constata-se que existe uma relação entre a climatologia e a abordagem geográfica do espaço, que compõe um campo do conhecimento em que as inter-relações entre a sociedade e o clima se configuram em um pressuposto básico para a compreensão das diferentes paisagens do planeta.

Além disso, o estudo do clima constitui uma das peças chave para a compreensão do amplo campo da ciência ambiental e seus desdobramentos. Ainda mais quando ocorrem eventos naturais extremos, tais como as ondas de calor que caracterizam situações adversas e que refletem sobre a qualidade de vida da população; que demanda por seu entendimento para estabelecer uma outra relação com o ambiente.

As ondas de calor constituem sequências de dias com temperaturas extremas, pois estas produzem impactos na sociedade, tanto de forma econômica ao prejudicar as produções agrícolas considerando que existem cultivos que são sensíveis ao calor extremo e prejudicial à saúde, pois pode intensificar processos inflamatórios e criar condições favoráveis ao desenvolvimento dos transmissores de doenças contagiosas. Portanto, demandam por análises para que possam colaborar com o planejamento, principalmente nas áreas da saúde humana e animal, produção agrícola e segurança hídrica. Alguns estudos no Brasil têm se dedicado à análise dos extremos de calor, principalmente sobre a região Sul. Ribeiro e Nunes (2011) analisaram dados de uma estação meteorológica na cidade de Pelotas, Rio Grande do Sul (RS) e foi verificado aumento na frequência de ondas de calor a partir da primeira década de 2000.

Streck et al. (2011) verificaram aumento da temperatura máxima a partir de meados da década de 1970 na cidade de Santa Maria (RS) e associaram este aumento com a fase quente da Oscilação Decadal do Pacífico (ODP).

Em virtude da dificuldade de caracterizar as ondas de calor por meio de um único critério, o presente trabalho tem como objetivo identificar períodos anômalos de calor, principalmente as ondas de calor, 
por meio de dois índices no decorrer do período de 1976 a 2015 no estado Paraná. Para tanto, foi considerada a base de dados da rede de estações do Instituto Agronômico do Paraná (IAPAR), que possui dados térmicos de 14 de estações e para o período determinado.

Rome et al. (2018) utilizaram diferentes métodos para a detecção de ondas de calor na região Auvergne-Rhône-Alpes, no presente trabalho também pretende-se avaliar o desempenho de duas metodologias distintas, comparar seus resultados e discutir suas implicações com o intuito de averiguar os episódios de calor extremos na área de estudo. Destaca-se que a importância desta análise recai sobre a possibilidade de ampliação do conhecimento do clima do Paraná, subsidiado na temperatura e contribui para a definição de estratégias de planejamento, pois os extremos de altas temperaturas e as ondas de calor prejudicam o potencial produtivo dos cultivos e sobre a saúde humana podem produzir câimbras, esgotamento, fadiga e até danos ao cérebro - AVC (Acidente Vascular Cerebral ); além de gerar impactos sobre a demanda de água.

\section{Mudanças e Variabilidade climática}

A variabilidade é uma característica inerente aos fenômenos climáticos, que não existem de forma isolada, pois resultam de múltiplas interações com o espaço geográfico e são intensificados na relação sociedade/natureza. Em diferentes escalas espaço temporais, qualquer modificação no clima repercute no meio físico e biológico.

Para uma melhor compreensão das mudanças climáticas, Nobre (2008) enfatiza que:

\footnotetext{
Mudança climática refere-se a qualquer mudança do clima que ocorra ao longo do tempo em decorrência da variabilidade natural ou da atividade humana. Esse uso difere da ConvençãoQuadro das Nações Unidas sobre Mudança do Clima, em que "mudança do clima" se refere a uma mudança do clima que possa ser atribuída direta ou indiretamente à atividade humana e que altere a composição da atmosfera global, sendo adicional à variabilidade climática natural observada ao longo de períodos comparáveis de tempo (NOBRE, 2008, p.09).
}

Nobre (2008) ainda relata que há dois tipos de impactos derivados das mudanças climáticas que, dependendo do nível de adaptação, podem-se distinguir em: Impacto potencial - todos os impactos que 
podem ocorrer devido às mudanças projetadas, sem considerar a adaptação e Impacto residual - os impactos das mudanças climáticas que podem ocorrer após a adaptação.

Atualmente as discussões que norteiam as pesquisas sobre as mudanças climáticas têm se tornado cada vez mais frequentes em função do vasto conhecimento disponível e das atuais evidências da ocorrência do aquecimento global decorrente da atividade humana. A organização Meteorológica Mundial (OMM) e o Programa das Nações Unidas para o Meio Ambiente (PNUMA) criaram o Painel Intergovernamental sobre Mudanças Climáticas (IPCC - Intergovernamental Pannel on Climate Change) para organizar e sistematizar as informações e elaborar relatórios periódicos sobre o estado da arte do conhecimento relativo à esta temática (IPCC, 2007). Os relatórios divulgados pelo IPCC em 2007, 2010 e 2013 afirmam que 90\% do aquecimento atmosférico observado na modernidade é provocado por atividades humanas (MENDONÇA, 2014).

Nestes relatórios o IPCC (2013; 2014) e o Painel Brasileiro de Mudanças Climáticas - PBMC (2014a, b) afirmam que é muito provável que a temperatura do ar aumente em toda a América do Sul, com o maior aquecimento no sul da Amazônia. As áreas consideradas mais vulneráveis são notadamente a Amazônia e o Nordeste do Brasil (MARENGO, 2014).

Apesar de todas as evidências de um cenário climático mais quente e como o ambiente científico não é uníssono, Molion (2008) destaca que o século XX foi marcado por períodos mais quentes e mais frios que podem ser explicados por causas naturais, possivelmente devido ao aumento da produção de energia solar e a redução do albedo planetário.

Neste sentido, segundo Molion (2008, p.18):

Além do efeito-estufa, outros processos físicos internos ao sistema terra-atmosfera-oceano, de não menor importância, controlam o clima. Variações da circulação atmosférica, associadas às variações da temperatura da superfície do mar (TSM) como, por exemplo, alterações na frequência de ocorrência de eventos El Niño-Oscilação Sul (ENOS), são outra causa de mudanças significativas na temperatura global. 
No entanto, Mendonça (2007) afirma que o principal responsável pelo aquecimento é o homem, que tem produzido um ambiente mais modernizado pelas atividades industriais, mudado a base energética e intensificado o consumo de combustíveis fósseis (carvão mineral e petróleo).

Para o IPCC $(2013,2014)$ não há mais dúvidas de que o aquecimento global está ocorrendo. Em seus últimos relatórios são destacadas, dentre outras mudanças, o aumento da ocorrência de dias e noites quentes desde a década de 1950, em associação com as atividades humanas e que é certo que esse aquecimento irá continuar até o final do presente século.

\footnotetext{
Mudanças climáticas naturais refletem apenas uma pequena parte de grandes e complexas mudanças que se operam no meio ambiente, sendo que as paisagens confirmam manifestações diretas dos câmbios que ocorrem na superfície do planeta no longo tempo da natureza. Grande parte da vegetação, solos, água, clima, etc., resultante do jogo de matéria e energia do universo, na condição natural, foi substituída por sistemas agropecuários e industriais-urbanos cada vez mais produtivos, marcando, de forma intensa, a alteração da superfície pelas distintas sociedades humanas (BORSATO; MENDONÇA, 2014 p. 50).
}

Para Borsato e Mendonça (2014) a ação humana enquanto agente do processo de mudanças ambientais globais tem se tornado cada vez mais importante para os diferentes grupos que tratam das mudanças do clima na era moderna.

Para Mendonça (2007), as consequências da elevação das médias térmicas corroboram para o aumento da precipitação, que pode intensificar a disseminação dos vetores de doenças como a málaria, dengue, coléra entre outras e as ondas de calor podem aumentar a umidade e a poluição, principalmente nos grandes centros urbanos, agravando os problemas respiratórios da população.

Um estudo mais recente do IPCC (2013) tem apontado uma elevação da temperatura na ordem de $1,5^{\circ} \mathrm{C}$ (otimista) a $4,5^{\circ} \mathrm{C}$ (pessimista) nas médias térmicas globais para o século XXI, alguns cenários tem apontado para uma elevação do nível médio dos mares na ordem de 0,09 (otimista) a 2 metros (pessimista) entre 1990 e 2100 , decorrente do derretimento de parte das calotas polares, das geleiras continentais e da expansão térmica provocada pela elevação média da temperatura (MENDONÇA, 2014). 
Os efeitos do aquecimento global não atingirão de forma igualitária todas as regiões do planeta, pois existem áreas que serão mais afetadas do que outras. Para constatar de que forma as mudanças climáticas estão ocorrendo, se estão se tornando mais intensas, faz-se necessário o desenvolvimento de estudos que aprofundem as pesquisas e contribuam para este conhecimento, principalmente em nível regional e local. No Brasil são verificadas tendências de aquecimento, especialmente nas temperaturas mínimas e temperaturas noturnas em grandes cidades (MARENGO, 2009). Diante do exposto, o presente artigo pretende contribuir com a análise do desempenho de diferentes métodos empregados no estudo da variabilidade térmica e na identificação de extremos de ondas de calor.

\section{Eventos extremos e as ondas de calor}

Atualmente muito se discute sobre o tema relacionado às mudanças climáticas e que, associado a essas mudanças, também poderá ocorrer um aumento do número de eventos extremos que se desdobrarão em prejuízos sociais e econômicos. As temperaturas extremas são condições térmicas rigorosas que podem indicar excesso de calor ou frio. São consideradas temperaturas extremas os registros máximos e mínimos verificados diariamente em estações meteorológicas (SANT'ANNA; NETO; TOMMASELLI, 2009).

Monteiro e Carvalho (2013) elaboraram uma síntese dos índices climáticos comumente empregados nos estudos de conforto térmico e destacam que tais índices procuram abarcar a variabilidade, os ritmos e as excepcionalidades dos eventos. Os índices climáticos absolutos, como próprio nome sugere, são compostos pelos valores absolutos das variáveis climáticas; enquanto que os índices climáticos relativos utilizam critérios de excepcionalidade baseados nos cálculos dos percentis das séries do período de referência e, por fim, os índices bioclimáticos estudam a relação entre os elementos climáticos, a saúde e o bem-estar dos seres humanos.

Dados discrepantes de um estado climático médio, considerados como eventos extremos, ocorrem em escalas temporais que variam de um período curto (dias) a períodos longos (milênios), embora os mais 
importantes para as atividades humanas são os extremos de curto prazo (relacionados com o tempo) e os de médio prazo (relacionados com o clima), que são eventos com potenciais impactos.

Segundo Marengo (2009), a caracterização dos eventos extremos de curto (tempo meteorológico) e longo prazo (clima) aponta, respectivamente, para aqueles relacionados às friagens, ondas de calor e frio, chuvas intensas, inundações, veranicos, etc. E os seus impactos variam de acordo com o setor, sazonalmente uma estação pode ser chuvosa ou extremamente chuvosa acompanhada por alta nas temperaturas que podem ter forte impacto sobre a população e em diferentes setores econômicos; dependendo da disponibilidade de água.

Para o citado autor os eventos extremos têm efeitos importantes na sociedade. Estudos sobre as mudanças climáticas na América do Sul apontam que nos últimos 50 anos as temperaturas em superfície aumentaram em $0,75^{\circ} \mathrm{C}$, em contrapartida as temperaturas mínimas têm aumentado em até $1^{\circ} \mathrm{C}$. O autor também enfatiza um aumento na frequência de ondas de calor e uma diminuição na frequência de noites frias: "Os dias frios, as noites frias e as geadas ficaram menos frequentes; enquanto os dias quentes, as noites quentes e as ondas de calor ficaram mais frequentes" (MARENGO, 2009, p. 2).

Extremos ou eventos raros têm grande importância na climatologia e na hidrologia e suas estimativas de ocorrência são imprescindíveis para o planejamento e desenvolvimento das atividades sujeitas aos efeitos adversos, especialmente sobre as estruturas de engenharia civil, a agricultura, saúde, entre outros (SANSIGOLO, 2008).

O quinto relatório do IPCC (2014) cita os impactos decorrentes de eventos climáticos extremos como, por exemplo, ondas de calor, secas, inundações, ciclones e incêndios florestais que revelam a significativa vulnerabilidade da sociedade atual. Os impactos de tais extremos relacionados ao clima incluem a alteração dos ecossistemas, a interrupção da produção de alimentos e abastecimento de água, danos às infraestruturas, morbidade e mortalidade e consequências para a saúde mental e para o bemestar humano. 
Há impactos relacionados às mudanças climáticas como alterações na biodiversidade, aumento no nível do mar e impactos na saúde, na agricultura e na geração de energia hidrelétrica que já podem estar afetando o Brasil; bem como o restante do planeta. O aquecimento também deve acentuar o problema das ilhas de calor em todas as grandes cidades, uma vez que prédios e asfalto retêm muito mais radiação do que as áreas não-urbanas (MARENGO; VALVERDE, 2009).

Historicamente, a variabilidade climática e os eventos extremos tiveram impactos negativos na população, aumentando a mortalidade e a morbidez nas áreas afetadas. Um dos aspectos que vem sendo estudado com relação aos possíveis efeitos das mudanças climáticas é a ocorrência mais frequente de eventos extremos de calor, que são identificados como "ondas de calor". O organismo humano poderá estar mais exposto a períodos de calor intenso, que se prolongam por vários dias consecutivos e constituem uma agressão ao mesmo, podendo conduzir ao agravamento de doenças. Da mesma forma os animais e as plantas possuem uma faixa ideal de conforto, na qual seu metabolismo funciona normalmente, mas quando os limites são ultrapassados provocam estresse e perda de produtividade.

São consideradas ondas de calor períodos de dias em que prevalece o calor excessivo, com duração equivalente a seis ou mais dias consecutivos. Segundo a Organização Meteorológica Mundial (OMM) uma onda de calor é caracterizada quando, em um intervalo de pelo menos seis dias consecutivos, a temperatura máxima diária é superior em $5^{\circ} \mathrm{C}$ ao valor médio diário no período de referência.

No entanto, diversas agências ou institutos meteorológicos adequam seus critérios às suas realidades climáticas, aplicando métodos diferenciados para mapear e analisar as ocorrências de ondas de calor em suas regiões de abrangência, conforme a percepção do conforto térmico regional.

No Paraná, Carbonieri et al. (2014) analisaram a ocorrência das ondas de calor utilizando uma adaptação do método da OMM e calcularam as médias da temperatura máxima para o período de outubro a março. 
Em Porto Alegre (RS), Cardia (2012) caracterizou as ondas de calor utilizando os métodos empregados por Araujo (1930), Machado (1950) e Conceição (1997), ou seja, quando as temperaturas absolutas ultrapassam valores considerados normais, para mínima e para máxima, durante o mínimo de três dias na estação de verão.

Conforme evidenciado nas referências, as condições térmicas e os seus extremos, como as ondas de frio e calor, causam impactos no espaço geográfico, principalmente quando se pensa em termos de planejamento urbano, do uso e ocupação do solo, no planejamento agrícola e na saúde humana. Dessa forma, trabalhos que abranjam discussões relacionadas à variabilidade térmica são importantes ferramentas de planejamento.

\section{Caracterização da área de estudo}

O presente trabalho analisa os eventos extremos em ondas de calor por meio da análise da temperatura máxima no estado do Paraná para o período de 1976 a 2015. O Paraná está localizado na região sul do Brasil e abrange uma área de $199.709 \mathrm{~km}^{2}$, entre $22^{\circ}$ e $26^{\circ}$ de latitude Sul e $48^{\circ}$ e $54^{\circ}$ de Longitude Oeste, atravessado pelo trópico de Capricórnio, situado em uma zona de transição do clima subtropical para o tropical (figura 1).



Figura 1: Localização do Estado do Paraná.Fonte: Pereira (2012, p.59). 
Os estudos voltados mais diretamente ao clima do Paraná começaram a ser desenvolvidos após os anos de 1960, porém já existiam trabalhos que levantavam elementos importantes para a compreensão de sua configuração climática. Em 1981 foi reeditado o livro de Maack que compreende um estudo detalhado sobre as diferentes paisagens paranaenses, com um capítulo inteiro dedicado ao clima do estado.

A partir da década de 1970 as investigações das condições climáticas do estado passaram a ser desenvolvidas, principalmente, mas não exclusivamente, pelo Instituto Agronômico do Paraná (IAPAR) (MENDONÇA, 1994).

O clima da região sul do Brasil apresenta características particulares e diferenciadas em relação à configuração climática brasileira como um todo, definido como sendo subtropical, de caráter mesotérmico, com grande amplitude térmica regional, farta distribuição anual das chuvas, sem ocorrência de período seco (NIMER, 1989).

O estado do Paraná está localizado na confluência dos principais sistemas atmosféricos da América do Sul e possui mais de um regime pluviométrico. Mendonça (1994) destaca que o Paraná apresenta uma distribuição pluvial anual com chuvas concentradas de setembro a abril com tendência ao regime tropical nas porções norte e noroeste e subtropical nas demais porções.

Dubreuil et al. (2017) procuraram atualizar a aplicação da classificação climática de Köppen ao Brasil e reafirmam a predominância do tipo climático Cfa no Paraná, ou seja, um clima subtropical com temperatura média no mês mais frio inferior a $18^{\circ} \mathrm{C}$ e temperatura média no mês mais quente acima de $22^{\circ} \mathrm{C}$, com verões quentes, geadas pouco frequentes e com tendência de concentração das chuvas no verão, mas sem estação seca definida.

De acordo com Nogarolli e Mendonça (2014), o tipo climático Cfa registra temperatura média no mês mais frio de 18 a $-3{ }^{\circ} \mathrm{C}$ (mesotérmico) e temperatura média no mês mais quente acima dos $22{ }^{\circ} \mathrm{C}$, com verões quentes, geadas pouco frequentes e períodos chuvosos concentrados nos meses de verão; mas 
sem estação seca definida. Enquanto que o tipo climático Cfb, predominante nas áreas mais elevadas do centro-sul do estado, é definido como temperado propriamente dito, apresentando temperatura média do mês mais frio igual as do tipo climático Cfa (18 e $-3^{\circ} \mathrm{C}$ - mesotérmico), com verões brandos e com temperatura média do mês mais quente inferior a $22^{\circ} \mathrm{C}$.

O período mais quente no estado é de dezembro a fevereiro quando as temperaturas máximas podem chegar a $40^{\circ} \mathrm{C}$, enquanto que o período mais frio é de junho a agosto com temperaturas mínimas atingindo valores negativos (MENDONÇA, 2004).

A figura 2 apresenta as médias das temperaturas máximas e mínimas e as médias das temperaturas absolutas no Paraná para o período de análise. As temperaturas médias das mínimas $\left(18,9^{\circ} \mathrm{C}, 19,6^{\circ} \mathrm{C}\right.$, $19,6^{\circ} \mathrm{C}$ e $\left.18,7^{\circ} \mathrm{C}\right)$ e as mínimas absolutas $\left(14,6^{\circ} \mathrm{C}, 16,1^{\circ} \mathrm{C}, 16,1^{\circ} \mathrm{C}\right.$ e $\left.14,1^{\circ} \mathrm{C}\right)$ apresentaram maiores valores nos meses de dezembro, janeiro, fevereiro e março respectivamente, com os menores valores ocorrendo entre os meses de junho a agosto $\left(11,9^{\circ} \mathrm{C}, 11,4^{\circ} \mathrm{C}\right.$ e $12,6^{\circ} \mathrm{C}$ respectivamente). As mínimas absolutas foram de $3,7^{\circ} \mathrm{C}, 3,4^{\circ} \mathrm{C}$ e $4^{\circ} \mathrm{C}$. A amplitude entre a média da mínima e a mínima absoluta que obteve maior destaque ocorreu nos meses de junho $\left(8,2^{\circ} \mathrm{C}\right)$ e julho $\left(8^{\circ} \mathrm{C}\right)$.

Ao analisar a temperatura média e a média das máximas, observa-se na figura 02 que as médias também ocorrem entre os meses de dezembro a março e as menores nos meses de junho e julho. As médias das máximas absolutas são as temperaturas mais quentes e apresentam valores mais elevados nos meses de outubro, novembro, dezembro e janeiro; variando entre $34^{\circ} \mathrm{C}$ a $34,2^{\circ} \mathrm{C}$, com máximas mais amenas nos meses de junho e julho. Nos meses de agosto, setembro e outubro a amplitude entre as máximas e as máximas absolutas apresenta mais destaque nesta análise, pois as médias das temperaturas máximas são de $25^{\circ} \mathrm{C}, 25,6^{\circ} \mathrm{C}$ e $27,7^{\circ} \mathrm{C}$ e a temperatura máxima absoluta de $31,7^{\circ}$ $33,3^{\circ} \mathrm{C}$ e $34,2^{\circ} \mathrm{C}$, com amplitude de $6,7^{\circ}, 7,7^{\circ} \mathrm{C}$ e $6,5^{\circ} \mathrm{C}$. A maior média da máxima absoluta ocorreu no mês de dezembro $\left(34,2^{\circ} \mathrm{C}\right)$ e a menor mínima absoluta aconteceu em julho $\left(3,4^{\circ} \mathrm{C}\right)$. 


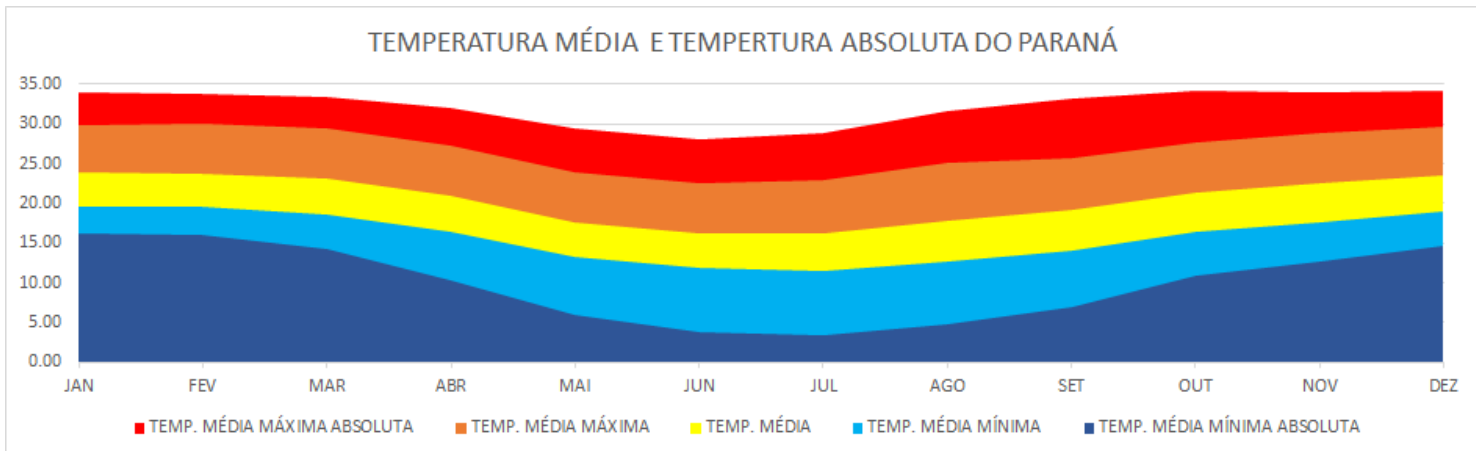

Figura 2: Média das temperaturas no estado do Paraná no período de 1976 a 2015. Fonte: IAPAR (2018). Organizado pela autora.

De acordo com a configuração do relevo, as médias térmicas podem variar localmente em virtude do gradiente vertical da Troposfera; que é de 0, $6^{\circ} \mathrm{C} / 100 \mathrm{~m}$ (MENDONÇA;DANNI-OLIVEIRA, 2009). 0 relevo do Paraná é classificado em cinco compartimentos regionais articulados com diferentes paisagens naturais que são: primeiro planalto ou Planalto de Curitiba, o segundo planalto ou Planalto de Ponta Grossa e o terceiro planalto ou planalto ou de Guarapuava, que se inclinam suavemente para O, NO e SO; além da Serra do Mar e do Litoral (figura 3) (MAACK, 2002). Esta configuração geral do relevo é um dos fatores mais importantes na caracterização climática do estado paranaense, pois contribui para a existência dos climas regionais predominantes, mas também para a configuração de climas locais.

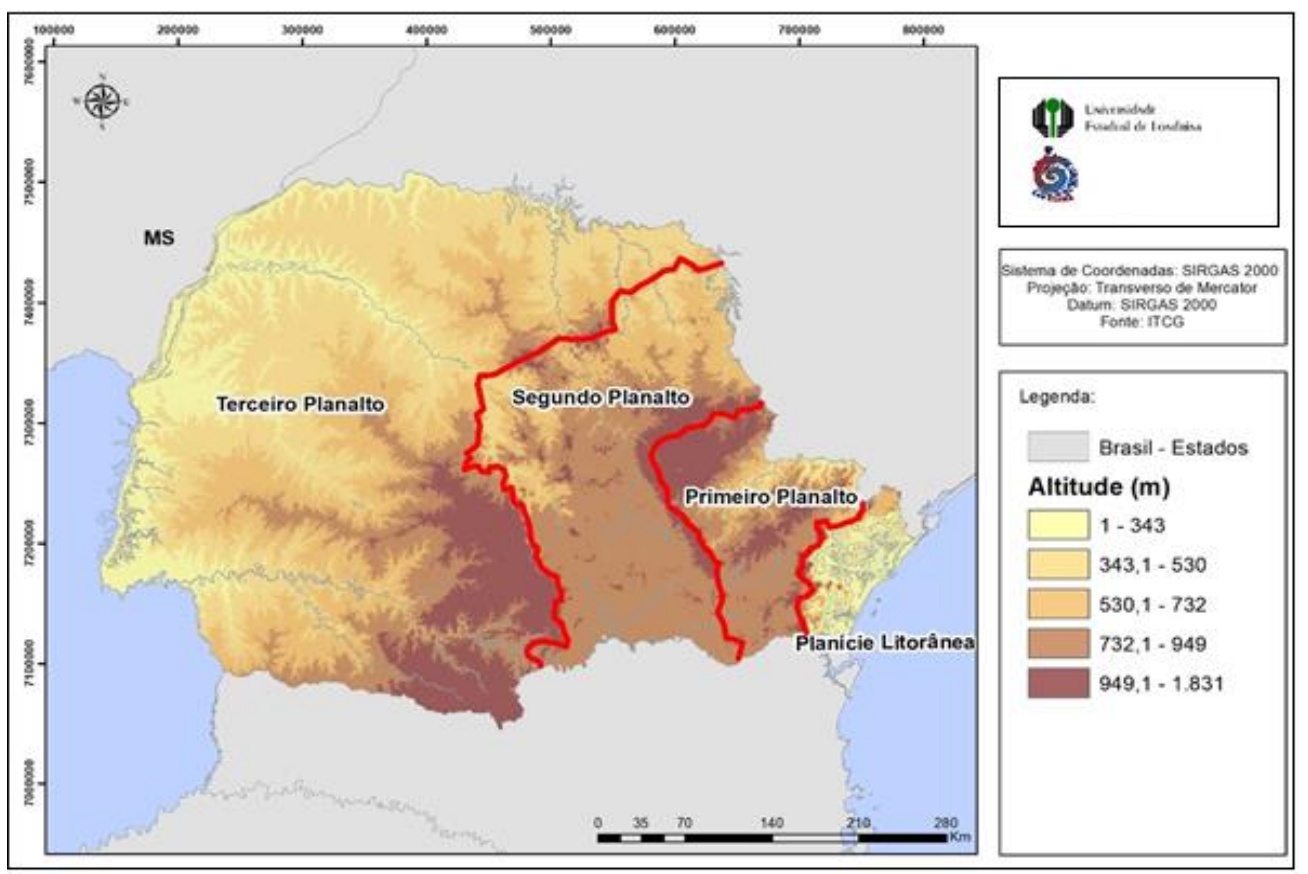

Figura 3: Mapa altimétrico do estado do Paraná e a divisão dos planaltos. Organizado por Villa (2018). 
Como ressaltado anteriormente, o Paraná apresenta uma pequena área litorânea localizada entre as latitudes $24^{\circ} 30^{`} \mathrm{~S}$ e $26^{\circ} 00^{`} \mathrm{~S}$ e longitudes $48^{\circ} 00^{`} \mathrm{~W}$ e $49^{\circ} 00^{`} \mathrm{~W}$, correspondendo a Planície Litorânea e parte da Serra do mar onde predomina o tipo climático Cfa. O mesmo tipo climático ocorre na Serra do Mar até 700m de altitude, nas áreas superiores à essas altitudes o clima passa ser descrito pelas características do tipo $\mathrm{Cfb}$ com precipitações mais frequentes, sendo que a temperatura média do mês mais quente não ultrapassa $22^{\circ} \mathrm{C}$ (VANHONI; MENDONÇA, 2008).

O clima do litoral é particularmente influenciado pelo oceano, bem como pela corrente aérea tropical que tem origem no centro de altas pressões do Atlântico, ao sul do trópico. Pelo seu lado ocidental esta massa aérea recebe a influência do fluxo das águas tépidas da Corrente do Brasil, que vem do Norte, onde domina a massa equatorial atlântica. No contato com estas águas, a corrente tropical atlântica aumenta sua instabilidade e o seu teor de umidade (KUNIYOSHI, 1993).

O Primeiro Planalto é o mais alto dos planaltos, com altitudes que vão de 850 a $1.300 \mathrm{~m}$. Nessa região encontramos remanescentes da Mata Atlântica com araucárias, típica de áreas altas e de clima ameno. O clima predominante neste planalto é o $\mathrm{Cfb}$, com verões quentes, invernos frios com temperaturas oscilando em torno de $17^{\circ} \mathrm{C}$ e inferiores a $20^{\circ} \mathrm{C}$, com pluviosidade superior a $1.200 \mathrm{~mm}$; podendo precipitar de forma torrencial.

O Segundo Planalto, também conhecido como Planalto de Ponta Grossa, é caracterizado por um relevo ondulado, com altitudes que variam de 300 a $1.250 \mathrm{~m}$ e as escarpas triássicas com variação de altitudes entre 750 e $775 \mathrm{~m}$, com cortes de vales na entrada da escarpa com $445 \mathrm{~m}$ de altitude no rio Ivaí, 490m no rio Tibagi e 735m no rio Iguaçu (MAACK, 2002).

O Terceiro planalto abrange cerca de $2 / 3$ do território paranaense e desenvolve-se como um conjunto de relevos planálticos, com inclinação geral para oeste-noroeste e subdivididos pelos principais afluentes do rio Paraná, atingindo altitudes médias de cimeira de 1.100 a $1.250 \mathrm{~m}$ na Serra da Esperança, declinando para altitudes entre 220 e 300 metros na calha do rio Paraná. Influenciadas por um clima do quaternário recente, as rochas eruptivas básicas deste planalto se decompõem em 
solos argilosos vermelho muito coesos, conhecidos como terra roxa. As altitudes variam entre 900 a $1.200 \mathrm{~m}$, onde predominava a vegetação original (Floresta Tropical e Mata das Araucárias) que hoje quase não existe mais (MAACK, 2002).

A maioria dos municípios paranaenses tem sua economia ligada à uma agricultura intensiva e vêm registrando, nos últimos anos, um acelerado crescimento urbano que contribuiu para a redução da mata nativa, tornando essas áreas cada vez mais suscetíveis aos eventos extremos, como o aumento da temperatura que contribui para a formação de ilhas de calor urbano e, consequentemente, impactos à saúde da população. Em virtude dos diferentes processos de ocupação das paisagens paranaenses, este território instiga a necessidade do entendimento da ocorrência de eventos climáticos extremos, principalmente aqueles ligados às ondas de calor e, para tanto, foram selecionados os municípios munidos de estações meteorológicas que registram temperaturas e que possuem bancos de dados completos, com um período uniforme para subsidiar a análise proposta e a comparação dos resultados obtidos com cada método de estudo; assim serão abordadas as metodologias aplicadas e seus resultados.

\section{Procedimentos metodológicos}

Para a concretização do presente estudo foram analisadas séries históricas de temperatura máxima do ar de quatorze estações meteorológicas da rede do IAPAR, distribuídas em diferentes regiões do estado (figura 4), que conta com as estações meteorológicas munidas de sensores térmicos e com uma série completa de dados. 0 período considerado para este estudo foi de 40 anos de dados diários para o recorte temporal de 1976 a 2015. 




Figura 4: Localização das estações meteorológicas utilizadas

Para um desdobramento das análises dos dados das temperaturas máximas diárias que permitisse a identificação das ondas de calor foram realizadas análises considerando os seguintes critérios:

1) MÉDIA HISTÓRICA DOS MESES DE OUTUBRO A MARÇO - estações de primavera e verão (P-V) - para o estabelecimento deste índice foi calculada a média geral das máximas no período histórico considerado (1976 a 2015) somente para os meses de outubro, novembro, dezembro, janeiro, fevereiro e março e, posteriormente, foi acrescentado $5^{\circ} \mathrm{C}$ a essa média e identificadas as ondas de calor;

2) ÍNDICE DIÁRIO (ID) - para a obtenção deste índice foram calculadas as médias diárias de cada dia do ano para o período de 1976 a 2015 , perfazendo um total de 365 valores. A cada valor médio diário foi acrescentado $5^{\circ} \mathrm{C}$ e, posteriormente, identificadas as ondas de calor que ocorreram em cada ano do período de referência.

A figura 5 ilustra os dois critérios utilizados, tomando como exemplo a estação de Londrina (PR). A média histórica das temperaturas máximas para as estações de primavera e verão foi de $34,4^{\circ} \mathrm{C}$, que marca uma reta uniforme para o período de outubro a março. Já o critério de cálculo das médias 
diárias das temperaturas máximas acompanha as variações de cada dia ao longo do ano, espelhando a condição extrema de acordo com os valores de temperatura nos dias analisados.

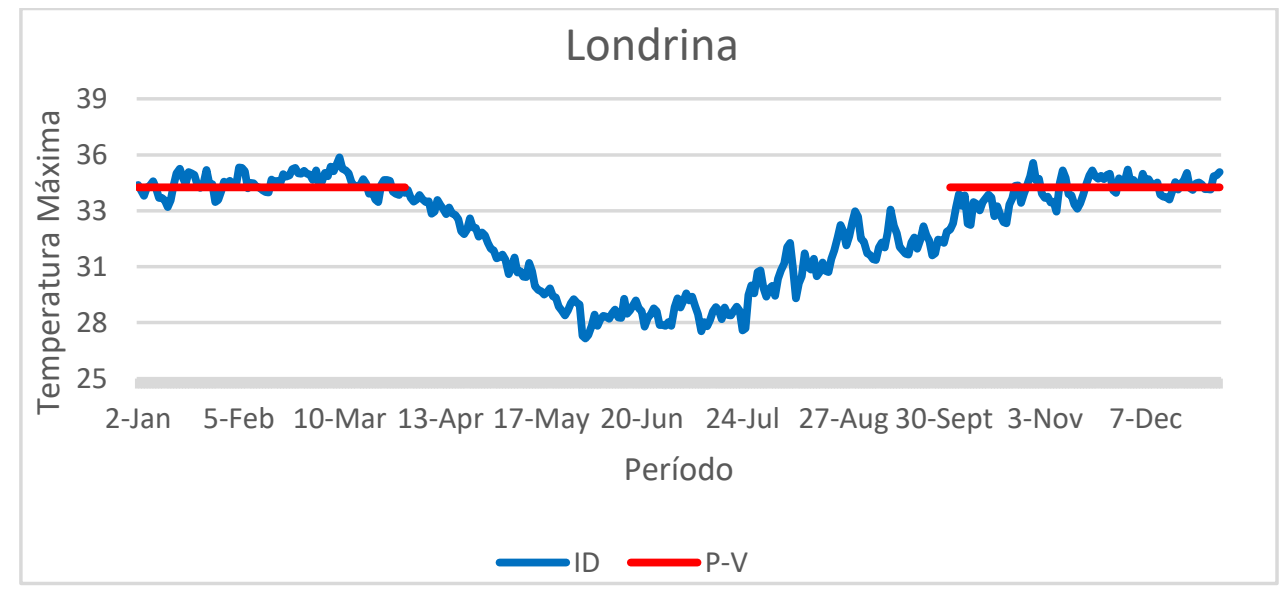

Figura 5. Demonstração dos critérios limite para identificação de períodos anômalos de calor aplicados aos dados históricos de Londrina (1976-2015). Índice Diário (ID)= média histórica diária $+5^{\circ} \mathrm{C}$; Primavera/Verão $(\mathrm{P}-\mathrm{V})=$ média histórica no período de outubro a março, compreendendo as estações de primavera e verão $+5^{\circ} \mathrm{C}$.

Com o critério que considera a primavera - verão (P-V) são destacadas as ondas de calor mais intensas no período quente, pois este não leva em conta os períodos frios do ano. Com o índice diário (ID) é possível comparar os desvios de temperatura em relação às médias que ocorrem durante todo o ano e, desta forma, espera-se retratar de maneira mais adequada os episódios anômalos com temperaturas mais elevadas. No entanto, nos períodos mais frios os aquecimentos anômalos podem não representar desconforto para a população, animais e cultivos agrícolas.

\section{Resultados e discussões}

Em um trabalho anterior, Kogima (2015) produziu uma análise sobre as ondas de calor subsidiada no método da Organização Meteorológica Mundial - OMM (baseado na média histórica simples calculada a partir da média diária geral das temperaturas máximas para o período de referência e, posteriormente, acrescenta-se $5^{\circ} \mathrm{C}$ a essa média; quando este valor ultrapassa a média por mais de 5 dias consecutivos é identificada uma onda de calor) e concluiu que o cálculo de uma única média para analisar toda a 
série, incluindo os meses com temperaturas amenas (abril a setembro), faz com que o valor da média diminua, aumentando a quantidade de ondas de calor detectadas em todos os locais analisados.

Para a elaboração do presente artigo o método descrito foi descartado, pois o intuito do presente estudo é analisar os episódios de ondas de calor que foram marcados por temperaturas mais elevadas. Portanto, optou-se pela aplicação do método Índice Diário (I/D) e do Primavera-Verão (P/V).

Como enfatizado anteriormente, o I/D permite caracterizar as anomalias de calor durante todo o ano, para o período de referêcia (tabela 01) e observar se ocorreu aumento no número de eventos em todas as estações do ano. $\mathrm{O}$ método $\mathrm{P} / \mathrm{V}$ identifica os episódios mais extremos, entre outubro a março e utiliza apenas uma única média para o período de referência em cada estação (figura 06).

A tabela 1 apresenta a ocorrência do número de ondas de calor ao longo de janeiro a dezembro com base no critério I/D. Por meio deste critério pode-se observar que o maior número de ondas ocorre nos meses de julho a setembro. As estações de Fernandes Pinheiro, Palotina, Cambará e Ponta Grossa apresentaram o maior número de episódios de ondas de calor $(20,19,18$ e 18 episódios respectivamente). Morretes, Londrina, Francisco Beltrão e Guarapuava registraram o menor número de ondas: 4, 12, 13 e 13 episódios no período de abril a setembro, respectivamente. 0 mês de setembro foi o mês com o maior número de anomalias de calor, registrando 107 eventos considerando o respectivo índice. 


\begin{tabular}{|c|c|c|c|c|c|c|c|c|c|c|c|c|c|c|}
\hline ESTAÇÕES & ÍNDICES & Jan & Fev & Mar & Abr & Mai & Jun & Jul & Ago & Set & Out & Nov & Dez & TOTAL \\
\hline \multirow{2}{*}{ BANDEIRANTES } & ID & & 1 & & & 2 & & 2 & 2 & 10 & 3 & 1 & & 21 \\
\hline & $\mathrm{P} / \mathrm{V}$ & 3 & 1 & & & & & & & & 1 & 1 & 1 & 7 \\
\hline \multirow{2}{*}{ BELA VISTA DO PARAISO } & ID & 1 & 1 & & & 1 & & 2 & 3 & 9 & 2 & 1 & & 20 \\
\hline & $\mathrm{P} / \mathrm{V}$ & 1 & 2 & & & & & & & & 2 & 1 & & 6 \\
\hline \multirow{2}{*}{ CAMBARÁ } & ID & 2 & 1 & & & 3 & 1 & 3 & 4 & 11 & 4 & 1 & 1 & 31 \\
\hline & $\mathrm{P} / \mathrm{V}$ & 2 & 2 & & & & & & & & 2 & 1 & 1 & 8 \\
\hline \multirow{2}{*}{ FERNANDES PINHEIRO } & ID & & 2 & 1 & 1 & 4 & 2 & 6 & 4 & 10 & 2 & 2 & & 34 \\
\hline & $\mathrm{P} / \mathrm{V}$ & 1 & 3 & 1 & & & & & & & & 1 & & 6 \\
\hline \multirow{2}{*}{ FRANCISCO BELTRÃO } & ID & & 1 & 1. & 1 & 3 & 2 & 6 & 4 & 3 & 1 & 11 & & 23 \\
\hline & $\mathrm{P} / \mathrm{V}$ & & 3 & & & & & & & & & 1 & & 4 \\
\hline \multirow{2}{*}{ GUARAPUAVA } & ID & & & & & 1 & & 3 & 4 & 6 & 1 & 1 & & 16 \\
\hline & $\mathrm{p} / \mathrm{V}$ & & 1 & & & & & & & & & 1 & & 2 \\
\hline \multirow{2}{*}{ JOAQUIM TÁVORA } & ID & 2 & 2 & 1 & & 1 & 0 & 5 & 2 & 9 & 3 & 1 & & 26 \\
\hline & $\mathrm{p} / \mathrm{V}$ & 1 & 2 & & & & & & & & & 1 & & 4 \\
\hline \multirow{2}{*}{ LONDRINA } & ID & 1 & 1 & & 1 & 1 & 1 & 1 & 4 & 7 & 2 & 1 & & 20 \\
\hline & $\mathrm{P} / \mathrm{V}$ & 1 & 2 & & & & & & & & 2 & 1 & & 6 \\
\hline \multirow{2}{*}{ MORRETES } & ID & 1 & 2 & & & 1 & 2 & 3 & & 1 & & 1 & & 11 \\
\hline & $\mathrm{P} / \mathrm{V}$ & 1 & 3 & & & & & & & & & & 1 & 5 \\
\hline \multirow{2}{*}{ PALOTINA } & ID & & 1 & & 2 & 4 & 5 & 5 & 5 & 9 & 1 & 1 & 11 & 34 \\
\hline & $\mathrm{P} / \mathrm{V}$ & & 1 & & & & & & & & 1 & 1 & 1 & 4 \\
\hline \multirow{2}{*}{ PARANAVAI } & ID & & & & 1 & 2 & 1 & 3 & 3 & 9 & 2 & 1 & 11 & 23 \\
\hline & $\mathrm{p} / \mathrm{V}$ & & 1 & & & & & & & & 1 & 1 & & 3 \\
\hline \multirow{2}{*}{ PLANALto } & ID & & 1 & 1 & & 7 & 6 & 5 & 6 & 6 & 2 & 1 & 1 & 36 \\
\hline & $\mathrm{P} / \mathrm{V}$ & & 3 & 1 & & & & & & & 1 & 1 & 1 & 7 \\
\hline \multirow{2}{*}{ PONTA GROSSA } & ID & & 1 & 1 & & 1 & 2 & 4 & 4 & 10 & 2 & & & 25 \\
\hline & $\mathrm{P} / \mathrm{V}$ & & 1 & 1 & & & & & & & 1 & 1 & & 4 \\
\hline \multirow{2}{*}{ UMUARAMA } & ID & & 1 & & 2 & 1 & 2 & 6 & 4 & 7 & 1 & 1 & & 25 \\
\hline & $\mathrm{P} / \mathrm{V}$ & 1 & 3 & & & & & & & & & & & 4 \\
\hline \multirow{2}{*}{ TOTAL ONDAS ID E P/V } & ID & 7 & 15 & 5 & 9 & 32 & 24 & 54 & 49 & 107 & 26 & 14 & 4 & 346 \\
\hline & $\mathrm{P} / \mathrm{V}$ & 11 & 28 & 3 & 0 & 0 & 0 & 0 & 0 & 0 & 11 & 12 & 5 & 70 \\
\hline
\end{tabular}

Tabela 1. Número de ocorrência de ondas de calor no estado do Paraná utilizando os critérios ID e P/V para o período de 1976 a 2015. (P-V): primavera -verão - (ID): índice diário.Fonte: Dados IAPAR- 2016. Organizado pela autora.

Com a aplicação do método $\mathrm{P} / \mathrm{V}$ (tabela 01), o mês de fevereiro foi o que registrou uma quantidade maior de ondas de calor (28 ondas), novembro registrou 12 ondas e outubro e janeiro 11 ondas respectivamente. Vale enfatizar que este método permitiu identificar 70 ondas de calor no período de análise.

O emprego do índice $\mathrm{P} / \mathrm{V}$ destaca os eventos de calor mais extremos, considerando apenas as médias do período de outubro a março, mas reduz de forma significativa o número de anomalias térmicas ocorridas no Paraná para o período analisado.

Por meio da figura 6 é possível verificar o número de anomalias de calor que foram registradas durante o período de análise considerando as temperaturas máximas. A aplicação destes métodos permitiu mapear as ocorrências de anomalias térmicas, sendo que o I/D detectou o maior número de registros e o $\mathrm{P} / \mathrm{V}$ o menor; pois este último destaca os eventos mais extremos.

Ao analisar o período frio, foram contabilizadas 275 ondas de calor entre os meses de abril a setembro no Paraná. Vale enfatizar que neste período ocorrem 79,5\% dos maiores registros das anomalias. 


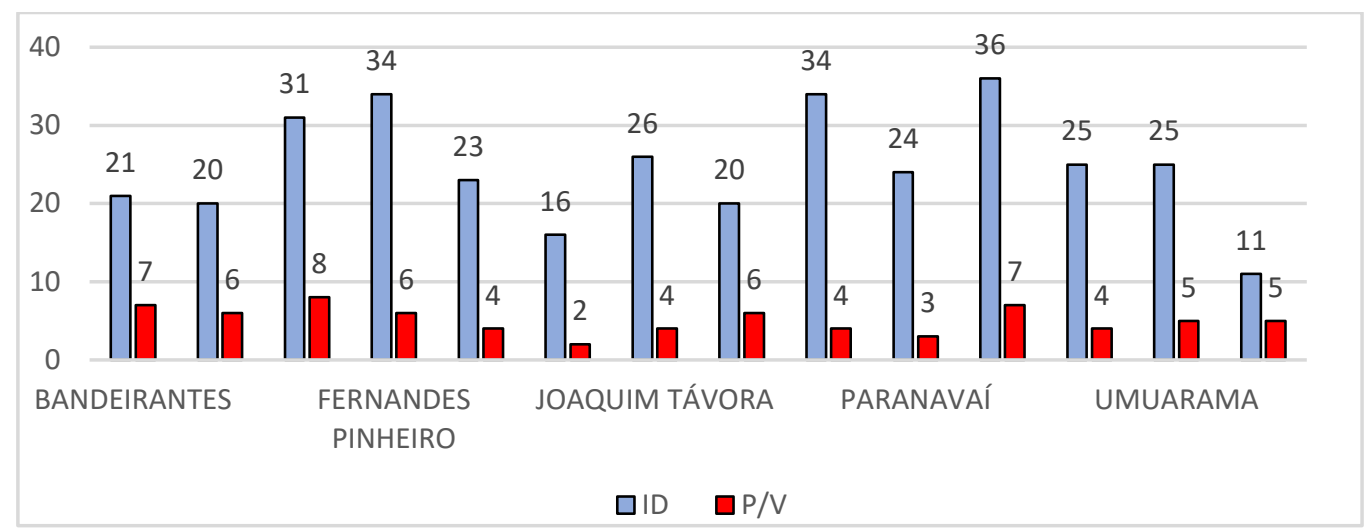

Figura 6. Número de ondas de calor identificadas por meio dos métodos aplicados às estações localizadas no Paraná para o período de 1976 a 2015. Fonte: Dados do IAPAR 2016.Organizado pela autora.

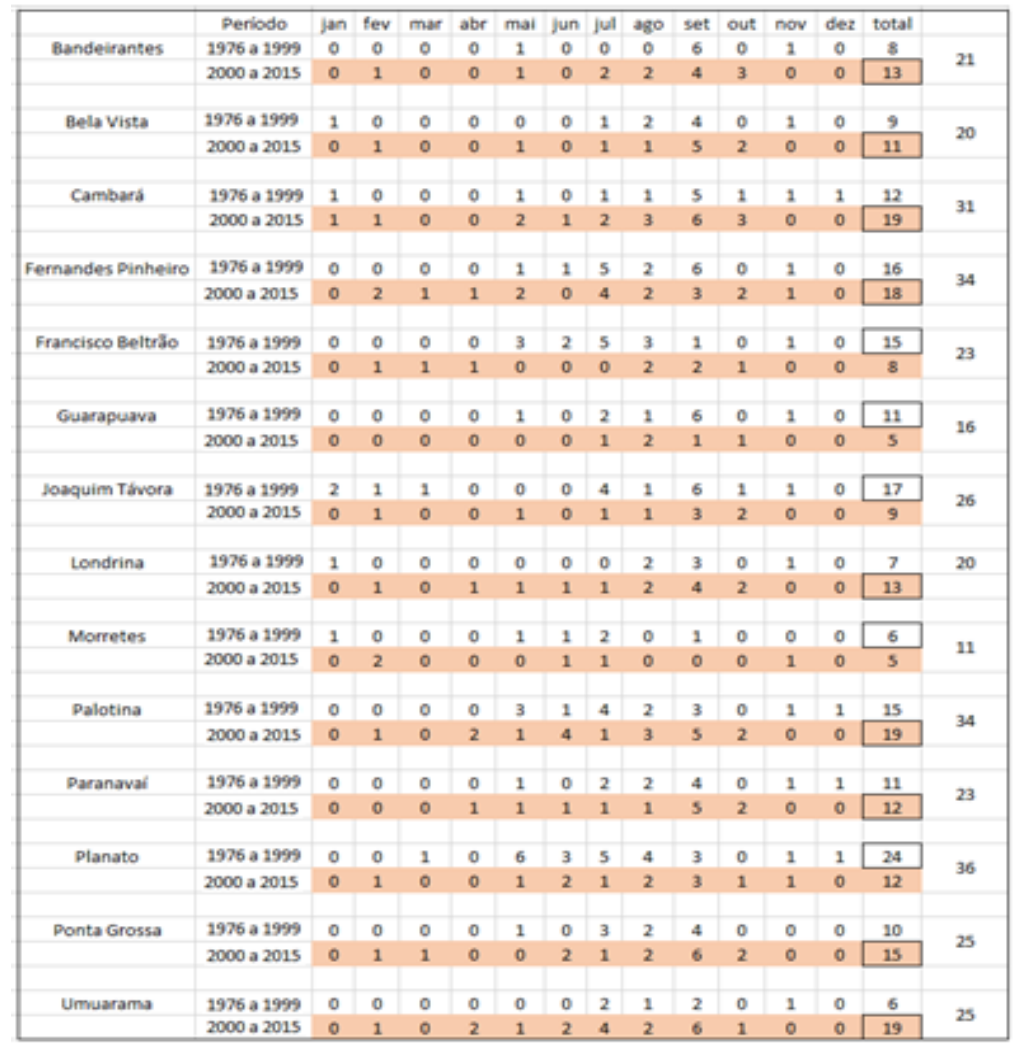

Tabela 2. Número de anomalias de calor para o Índice Diário, divididos em dois períodos de análise. Fonte: Dados IAPAR2016. Organizado pela autora.

No tabela 2 foram computados os números de eventos detectados com a aplicação do método I/D e pode-se analisar de forma conjunta se houve aumento dos registros ao longo dos anos. Entre 1976 e 1999 (24 anos, 60\% do período) ocorreram 167 eventos acima da média, a partir dos anos 2000 até 2015 (16 anos, 40\% do período) foram registrados 178 eventos acima da média. Este fato contribui 
para demonstrar que houve aumento no número de anomalias térmicas após a década de 2000 no Paraná.

Para nove estações foram detectados maiores registros após o ano de 2000, no decorrer dos meses de agosto a outubro: Umuarama com 19 de 25 eventos identificados após o ano 2000; Cambará 19 de 31; Londrina 13 de 20; Bandeirantes 13 de 21; Ponta Grossa 15 de 25; Palotina 19 de 34; Bela Vista 11 de 20 e Fernandes Pinheiro 18 de 34 (tabela 2).



Tabela 3. Número de anomalias de calor no período de referência considerando o método I/D. Fonte: Dados IAPAR- 2016. Organizado pela autora.

A tabela 3 apresenta a ocorrência anual das ondas de calor para o método I/D. Por meio deste índice, apenas 7 anos do período de análise não registraram a ocorrência de ondas de calor. Os anos com maior destaque em número de ocorrências foram: 1985, 1988, 1994, 1995, 2006, 2014 e 2015, anos considerados extremamente quentes. Nos anos de 1988, 1994 e 1995 houve ocorrência do fenômeno El Niño de intensidade moderada. Em 2006 ocorreu El Niño de fraca intensidade e em 2015 o fenômeno foi de forte intensidade. 0 ano de 1985 caracterizou um período de ocorrência do fenômeno La Niña, considerado o ano mais seco do período em análise. E 2014 é caracerida como um ano habitual (CPTEC/INPE, 2016). 
Com a análise da tabela 4, verifica-se que a ocorrência de ondas de calor obtidas com o índice $\mathrm{P} / \mathrm{V}$ foi de $37,5 \%$ do período analisado. Com destaque para os anos de 1985 e 2014 com os maiores registros de anomalias térmicas. As estações com maiores temperaturas em ondas de calor foram Palotina $\left(36,5^{\circ} \mathrm{C}\right)$; Cambará $\left(35,8^{\circ} \mathrm{C}\right)$; Bandeirantes $\left(35,8^{\circ} \mathrm{C}\right)$; Paranavaí $\left(35,7^{\circ} \mathrm{C}\right)$ e Joaquim Távora $\left(35,2^{\circ} \mathrm{C}\right)$, estações localizadas no norte, noroeste e oeste do estado, ou seja, na região mais quente (tabela 5). Mas outro fator que também pode influenciar no registro destes extremos térmicos é a altitude das estações, que são mais baixas e variam entre $310 \mathrm{~m}$ a $512 \mathrm{~m}$.

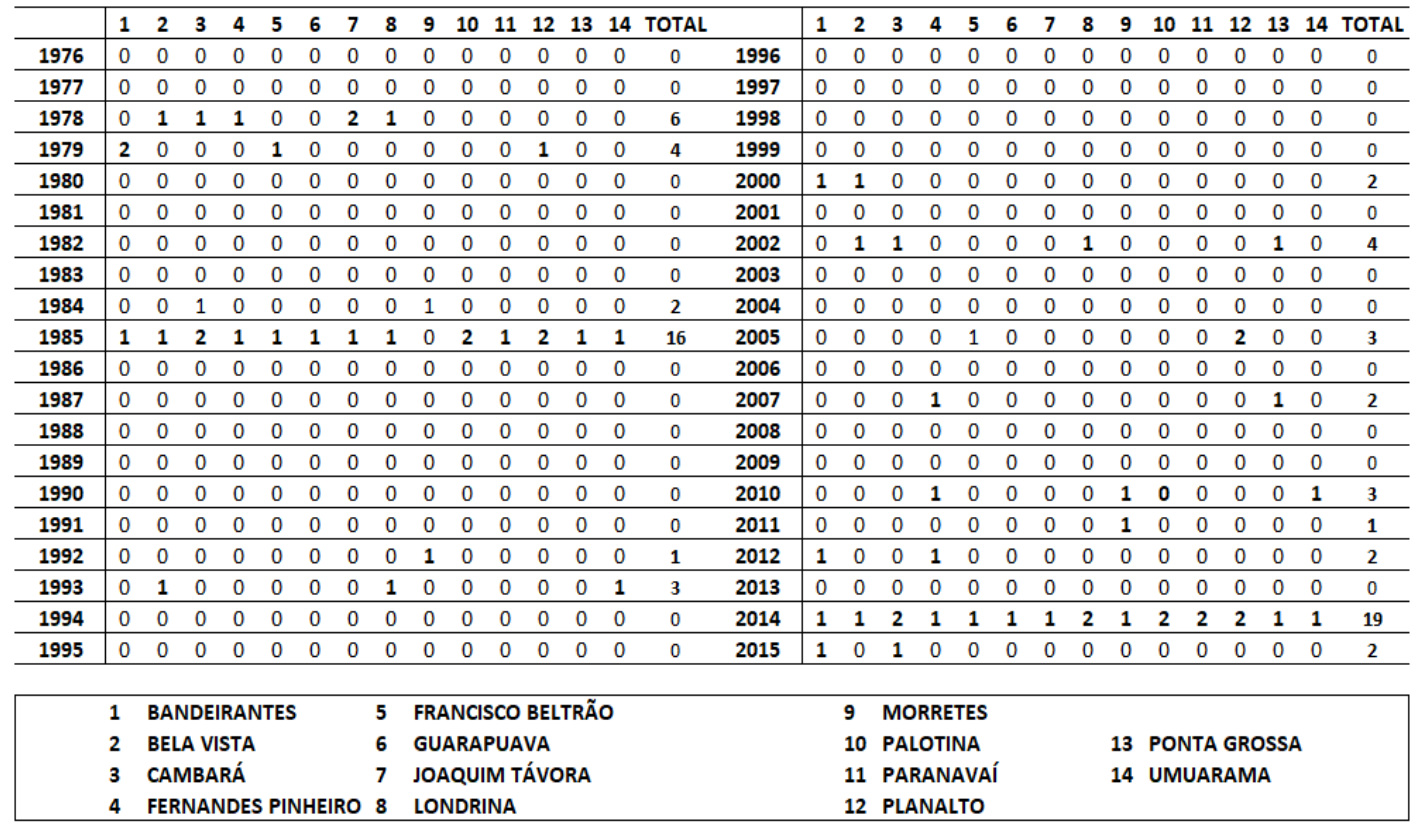

Tabela 4. Número de anomalias de calor no período de referência considerando o método P/V. Fonte: Dados IAPAR- 2016. Organizado pela autora

\begin{tabular}{|c|c|c|c|c|c|c|c|c|c|}
\hline ESTAÇÕES & Média ID & $+50 \mathrm{C}$ & Média P/V & $+50 \mathrm{C}$ & ESTAÇÕES & Média ID & $+50 \mathrm{C}$ & Média P/V & $+50 \mathrm{C}$ \\
\hline BANDEIRANTES & 28.7 & 33.7 & 30.8 & 35.8 & LONDRINA & 27.3 & 32.3 & 29.4 & 34.4 \\
\hline BELA VISTA DO PARAÍSO & 27.1 & 32.1 & 29.2 & 34.2 & MORRETES & 26.3 & 31.3 & 28.7 & 33.7 \\
\hline CAMBARÁ & 28.8 & 33.8 & 30.8 & 35.8 & PALOTINA & 28.8 & 33.8 & 31.5 & 36.5 \\
\hline FERNANDES PINHEIRO & 24.0 & 29.0 & 26.6 & 31.6 & PARANAVAÍ & 28.4 & 33.4 & 30.7 & 35.7 \\
\hline FRANCISCO BELTRÃO & 26.0 & 31.0 & 29.1 & 34.1 & PLANALTO & 27.3 & 32.3 & 30.1 & 35.1 \\
\hline GUARAPUAVA & 23.5 & 28.5 & 25.9 & 30.9 & PONTA GROSSA & 24.0 & 29.0 & 26.4 & 31.4 \\
\hline JOAQUIM TÁVORA & 28.0 & 33.0 & 30.2 & 35.2 & UMUARAMA & 27.9 & 32.9 & 30.2 & 35.2 \\
\hline
\end{tabular}

Tabela 5: Temperaturas médias e em ondas de calor para os métodos ID e P/V. Fonte: Dados IAPAR- 2016. Organizado pela autora.

Com o desenvolvimento deste trabalho pode-se constatar a influência da altitude nos resultados obtidos, pois localidades com maiores altitudes como Guarapuava (1058m), Ponta Grossa (880m) e Fernandes Pinheiro (893m) têm as médias das temperaturas máximas menos elevadas $\left(23,2^{\circ} \mathrm{C}, 24^{\circ} \mathrm{C}\right.$ 
e $24,1^{\circ} \mathrm{C}$ respectivamente). Enquanto que aquelas com altitude menores, como Morretes (59m), Palotina (310m), Planalto (400m), Bandeirantes (440m) e Cambará (450m) apresentam as médias das temperaturas máximas maiores $\left(26,3^{\circ} \mathrm{C}, 28,8^{\circ} \mathrm{C}, 27,3^{\circ} \mathrm{C}, 28,7^{\circ} \mathrm{C}, 28,9^{\circ} \mathrm{C}\right.$ respectivamente).

De acordo com os dados do IAPAR utilizados no presente estudo, o pico máximo das máximas absolutas ocorreu no ano de 1985, entre os dias 16 e 17 de novembro para 12 estações; com exceção de Umuarama e Morretes. Neste período a umidade relativa do ar registrada foi de 19,7\% em Bela Vista do Paraíso até 43\% em Francisco Beltrão e não houve registro de precipitação.

Em Morretes o pico máximo ocorreu em 19/11/2009 com umidade de 76,4\% e sem ocorrência de precipitação. Em Umuarama ocorreu em 11/03/2005 com umidade de 55,8\% e um registro de 4,5 mm de precipitação pluvial.

Por meio destas informações adicionais e considerando os picos das temperaturas máximas no estado, mesmo que em algumas estações e em períodos distintos, foi possível verificar que durante os eventos térmicos extremos geralmente não ocorre precipitação (com exceção de Umuarama, porém os valores pluviométricos registrados foram baixos - apenas $4,5 \mathrm{~mm}$ ) e a umidade relativa do ar era inferior ou próxima de 50\% (exceção na estação de Morretes em virtude da maritimidade).

As ocorrências de picos extremos de temperatura, conforme observado, ocorreram em dias de céu claro, com nenhuma ou pouca precipitação e baixa umidade relativa do ar. A disponibilidade de água na forma de precipitação reduz a amplitude térmica e dificulta a configuração de ondas de calor, pois segundo Mendonça e Danni-Oliveira (2007) os dias com nebulosidade alta associada à umidade relativa do ar acima de 80\%, com ou sem precipitação, diminuem a amplitude térmica. As nuvens impedem que a radiação solar entre de forma direta no sistema superfície-atmosfera dificultando o aumento brusco da temperatura durante o dia e, ainda, funcionam como bloqueio gradual para a perda de energia durante a noite; não permitindo que a temperatura diminua rapidamente. Sendo assim, em dias nublados ou com ocorrência de precipitação as ondas de calor se tornam remotas. 
Ely e Fortin (2017) produziram uma análise da variabilidade e das tendências dos extremos térmicos baseada em uma dezena de índices climáticos calculados a partir de dados térmicos das redes do Instituto Nacional de Meteorologia (INMET) e do IAPAR para dez estações localizadas em duas regiões distintas do Paraná. E constataram que os valores máximos mensais da temperatura diária (TXx) apresentam uma tendência ascendente significativa para as estações localizadas no norte do estado (Bela Vista do Paraíso, Londrina IAPAR, Londrina e Umuarama), mas diminui nas estações de Paranaguá e Lapa (no leste). As temperaturas mínimas diárias (TNn) também aumentaram nas estações analisadas, com exceção da Lapa (localizada no leste), que apresentou uma tendência estatisticamente significativa. Ou seja, em algumas regiões do Paraná as temperaturas noturnas estão se tornando mais elevadas, o que indica que os invernos estão se tornando mais amenos.

Ricce et al. (2009) também mostram que os invernos estão iniciando mais tarde e terminando mais cedo na região de Londrina.

Com a aplicação dos dois métodos demonstrados neste artigo foram constatados resultados diferentes. $\mathrm{O}$ índice $\mathrm{P} / \mathrm{V}$ desconsidera em seu cálculo as médias do período frio, o que gera um aumento da média calculada e possibilita detectar episódios de calor extremo, mas não permite identificar anomalias de calor no período do inverno.

O método I/D permite analisar cada dia do ano no período de referência, pois para cada dia é calculada uma média; propiciando assim observar as anomalias que ocorreram durante todo ano.

\section{CONSIDERAÇÕES FINAIS}

O desenvolvimento deste trabalho permitiu identificar e analisar os períodos anômalos de calor e eventos extremos térmicos no estado Paraná. $\mathrm{O}$ método I/D foi desenvolvido para analisar os períodos anômalos de calor para o recorte temporal considerado (1976 a 2015) e possibilitou identificar as anomalias climáticas que ocorreram nos meses de abril a setembro (frio). Este fato indica que as 
temperaturas mínimas estão aumentando e tornando o inverno menos rigoroso no estado; corroborando com os resultados de Ricce et al. (2009) e de Ely e Fortin (2017).

As ondas de calor mais expressivas identificadas por meio do método I/D foram observadas nos municípios de Planalto, Palotina, Fernandes Pinheiro e Cambará. Este método foi apropriado para analisar as anomalias de calor que ocorreram no período frio (outono/inverno). Das 346 ondas de calor registradas no período de análise, 275 ocorreram entre os meses de abril a setembro; sendo que este último mês se destaca com um total de 107 ondas.

$\mathrm{O}$ método $\mathrm{P} / \mathrm{V}$ permite a identificação das ondas mais quentes, pois utiliza somente os dados de primavera e verão. Com este método foi constatado que as estações que registraram o maior número de ondas de calor foram: Cambará, Bandeirantes, Planalto, Bela Vista do Paraíso e Londrina. E o mês com os maiores registros foi fevereiro com 28 ondas, ou seja, $28 \%$ das ondas de calor ocorreram em apenas um mês.

Os resultados obtidos mostraram que os episódios de ondas de calor ocorrem com frequência no estado do Paraná e, dependendo do critério utilizado, a forma de análise e a quantidade de anomalias detectadas produzem resultados variados. Tal análise propiciou apontar que os períodos de temperaturas médias máximas vêm ocorrendo com maior frequência após a década de 2000, resultado verificado para os dois métodos empregados.

Para a análise das ondas de calor considerando apenas o período $\mathrm{P} / \mathrm{V}$, somente os eventos mais extremos foram detectados, pois somente a média do período quente é utilizada; logo a quantidade de períodos anômalos diminui consideravelmente.

Finalmente, com a aplicação do critério I/D identifica-se um outro padrão de ocorrência de ondas de calor no Paraná. Como a referência é cada dia do ano, sempre que a temperatura máxima ultrapassa em 5oC o valor médio por 6 dias consecutivos ou mais, caracteriza-se um período anômalo de calor. Assim, com esse critério são detectados períodos anômalos de calor durante todo o ano, os quais nem 
sempre estão associados com desconforto térmico para a sociedade, animais e vegetais. No entanto, a ocorrência de períodos quentes anormais, tendo como referência a época do ano, é importante pois pode facilitar a proliferação de doenças, insetos vetores ou prejudicar o repouso invernal de espécies frutíferas. E, também, se configura num importante indicador da variabilidade climática associada às mudanças climáticas.

Portanto, destaca-se que este último critério propiciou detectar de forma mais precisa o aquecimento anômalo nos meses mais frios do ano, ou seja, entre abril e setembro. De acordo com as análises apresentadas, cerca de $70 \%$ dos períodos anômalos de calor ocorrem no intervalo destes meses em todas as estações analisadas, fator que mostra o aumento das temperaturas máximas, ocasionando invernos mais amenos. Este método pode ser o mais adequado para avaliar as anomalias climáticas em outras regiões do país, pois considera mensalmente as anomalias durante o decorrer do ano.

Conclui-se esta pesquisa olhando para o futuro, sugerindo a necessidade de providenciar análises em escalas espaciais menores, que considerem os aspectos locais da orientação do relevo, uso e ocupação do solo, dinâmica dos ventos e influência das massas de ar que podem deflagrar a ocorrência dos episódios de ondas de calor; além de estudos que possam produzir cenários dos impactos de um clima mais quente sobre a saúde da população, a incidência de doenças em seres humanos e nas espécies vegetais, dentre outras atividades socioeconômicas desenvolvidas no estado.

\section{REFERÊNCIAS}

BORSATO, V.; MENDONÇA, F. A Dinâmica Atmosférica no Centro-Sul do Brasil e as Mudanças Climáticas. In MEndonÇA F. (org.) Climas do Sul: Em Tempos de Mudanças Climáticas Globais. Jundiaí, Paco Editorial, p.47-88, 2014

CARDIA, V. C. Climatologia das Ondas de Calor em Porto Alegre- RS: 1961 a 2010. 2010/2. (72 páginas) Trabalho de conclusão de curso em Geografia. Universidade Federal do Rio Grande do Sul. Porto Alegre. 2012.

CIOCCI, Marcus V., Reflexos do Excesso de Calor na Saúde e na Redução da Produtividade, Add Eletronics, Compilado a partir das publicações: Excessive Heatand Worker Safety - Universidade da Pensilvânia e NASA. 2004.

CPTEC/INPE - Centro de Previsão de Tempo e Estudos Climáticos. Disponível em: http://enos.cptec.inpe.br./. Acesso em 07 ago. 2016.

ELY, D. F.; DUBREUIL, V. Análise das tendências espaço temporais das precipitações anuais para o estado do Paraná. Revista Brasileira de Climatologia, v.21, n.13, p 553-569, jul/dez. 2017 
ELY, D. F., FORTIN, G. Variabilité et Tendances des Extrêmes Thermiques Dans L'état du Paraná, Brésil (1970-2015). Actes...XXXème colloque de l'Association Internationale de Climatologie, Sfax 03-06 juillet, 2017.

Instituto Agronômico do Paraná. Disponível em:

http://www.iapar.br/modules/conteudo/conteudo.php?conteudo=863 Acesso em: 8 abril 2014.

Intergovernmental Panel on Climate Change. Climate Change 2013, the Physical Science Basis.2013. Disponível em: http://www.climatechange2013.org/images/uploads/WGI_AR5_SPM_brochure.pdf Acesso em: 18 jan. 2017

Intergovernmental Panel on Climate Change 2014. Synthesis Report. Summary for Policymakers. 2014. Disponível em: http://www.ipcc.ch/pdf/assessment-report/ar5/syr/AR5_SYR_FINAL_SPM.pdf. Acesso em: 17 ago. 2017.

KOGIMA, K. C. Análise de índices para a identificação de anomalias de calor em séries de dados meteorológicos. 2015. (62 páginas). Trabalho de Conclusão de curso em Geografia - Universidade Estadual de Londrina, Londrina, 2015.

KOGIMA, K. C. Anomalias de calor associadas a variabilidade térmica no estado do Paraná. 2018. (121 páginas). Dissertação (mestrado em Geografia) - Universidade Estadual de Londrina, Londrina, 2018.

KUNIYOSHI, Y. S. Aspectos morfo-anatômicos do caule, raiz e folha de tabebuia cassinoides (lam.) De (bignoniaceae) em diferentes fases sucessionais no litoral do Paraná. (147 páginas) Tese (Doutorado em Engenharia Florestal) Ciências Agrárias, Universidade Federal do Paraná. Curitiba, 1993.

MAACK, R. Breves notícias sobre a geologia dos Estados do Paraná e Santa Catarina. Brazilian Archives of Biologyand Technology, p. 169-288, 2002.

MAREnGO, J. A. Mudanças Climáticas Globais e Seus Efeitos Sobre a Biodiversidade: Caracterização do Clima Atual e Definição das alterações Climáticas para o território Brasileiro ao Longo do Século XXI. Brasília. 2006. Disponível em: http://www.mma.gov.br/estruturas/imprensa/_arquivos/livro\%20completo.pdf Acesso em: 14 de Abril 2017

MARENGO, J. A. Impactos de extremos relacionados com o tempo e o clima - Impactos sociais e econômicos. Boletim do Grupo de Pesquisa em Mudanças Climáticas -GPMC. Instituto Nacional de Pesquisas Espaciais -INPE. Centro de Ciências do Sistema Terrestre -CCST n. 8 - maio de 2009 - Edição Especial.

MAREnGO, J. A. O futuro clima do Brasil. Revista USP, São Paulo. v. 103, p. 25-32, 2014.

MARENGO, J.A.; CAMARGO, C.C. Surface air temperature trends in Southern Brazil for 1960-2002. International Journal of Climatology, v. 28, n. 7, p. 893-904, 2008.

MARENGO, J; VALVERDE, M. C.. Caracterização do clima no Século XX e Cenário de Mudanças de clima para o Brasil no Século XXI usando os modelos do IPCC-AR4 in Revista Multiciência, Campinas, n. 8, p. 5- 28, maio 2009. Acesso em: set. 2017.

MENDONCA, F. A. Aquecimento Global e suas manifestações regionais e locais: alguns indicadores da região Sul do Brasil. Revista Brasileira de Climatologia, v. 2, p. 71-86, 2007.

MENDONÇA, F; DANNI-OLIVEIRA, I. M. Climatologia: noções básicas e climas do Brasil. São Paulo: Oficina de Textos, 2007.

MEndonCA, F. A. 0 Clima e o Planejamento Urbano de Cidades de Porte Médio e Pequeno. Proposição Metodológica para Estudo e sua Aplicação à Cidade de Londrina/Pr. 1994. Tese (Doutorado) - Faculdade de Filosofia, Letras e Ciências Humanas, Universidade de São Paulo. São Paulo. 
MENDONCA, F. A. Clima, tropicalidade e saúde: Uma perspectiva a partir da intensificação do aquecimento global. Revista Brasileira de Climatologia, v. 1, p. 97-110, 2006.

MOLION, L. C. B. Aquecimento global: uma visão crítica. Revista Brasileira de Climatologia, v.3/4, p. 7-24. 2008.

MONTEIRO, A. CARVALHO, V. Uma abordagem metodológica para avaliação de eventos climáticos extremos. IN: TRINDADE et al. (ORG) Climatologia urbana e regional: questões teóricas e estudos de caso. $1^{\text {a }}$ edição. São Paulo: Outras expressões-Geografia em Movimento, p. 117-142, 2013.

NIMER, E. Climatologia do Brasil. Instituto Brasileiro de Geografia e Estatística, Rio de Janeiro, 1989.

NOBRE, C. A. Mudanças Climáticas e o Brasil - Contextualização. Parcerias Estratégicas. Brasília /DF. n.27. dezembro. 2008 .

NOGAROLI, M.; MENDONÇA, F. Mudanças Climáticas Globais e Variabilidade Climática no Estado do Paraná. In MENDONÇA F. (org.) Climas do Sul: Em Tempos de Mudanças Climáticas Globais. Jundiaí, Paco Editorial, 2014. p.141173.

RIBEIRO, B.Z.; NUNES, A.B. Variação temporal das ondas de calor na cidade de Pelotas-RS. Encontro Sul Brasileiro de Meteorologia. IV, 2011. Pelotas (Rs)

RICCE, W. da S. et al. Análise de tendências na temperatura e precipitação em Londrina, estado do Paraná. In: XV Congresso Brasileiro De Agrometeorologia. 2009.

ROME, S. et al. Les services climatiques pour faciliter l'analyse des temperatures extremes a l'echelle locale: cas d'etude en auvergne-rhone-alpes, france. In: Actes...XXXIe Colloque de L'association Internationale de Climatologie. 2018, Nice: l'UMR 7300 ESPACE (CNRS / Université de Nice Sophia Antipolis) 2018. p.219-224.

SANSIGOLO, C. A. Distribuições de Extremos de Precipitação Diária, Temperatura Máxima e Mínima e Velocidade do Vento em Piracicaba, Sp (1917-2006). Revista Brasileira de Meteorologia, v.23, n.3, 341-346, 2008.

STRECK, N.A.; GABRIEL, L.F.; BURIOL, G.A.; HELDWEIN, A.B.; DE PAULA, G.M. Variabilidade interdecadal na série secular de temperatura do ar em Santa Maria, RS. Pesquisa Agropecuária Brasileira, v. 46, n. 8, p. 781-790, 2011

VANHONI, F.; MENDONÇA, F. O clima do litoral do estado do Paraná. Revista Brasileira de Climatologia, v. 3/4, p. 4964,2008 . 